\title{
Traducir literatura infantil y juvenil de temática árabe e islámica al castellano: editoriales, normas preliminares y polisistemas literarios en contacto
}

\section{The Translation of Children's and Young Adult Literature focusing on Arabic and Islamic issues: Publishers, Preliminary Norms \& Interrelated Polysystems}

\section{Beatriz SOTO ARANDA}

Universidad Rey Juan Carlos

beatriz.soto@urjc.es

Recibido febrero-2019. Revisado: marzo-2019. Aceptado: mayo-2019.

Resumen: Desde los estudios poscoloniales y los de la Manipulación (Kruger 2012), el análisis de la traducción de la LIJ constituye un campo de análisis idóneo para estudiar la construcción de la Otredad en las sociedades contemporáneas, particularmente por lo que a las minorías culturales se refiere, pues las relaciones entre culturas no son neutrales, como tampoco los intercambios comunicativos; existen relaciones de poder, y la traducción, como una fuerza conformadora de la cultura (Venuti 1998), no es ajena a este hecho, ni es inocente (Lefevere y Bassnett 1990).

En este sentido, La LIJ de temática árabe e islámica ha tenido un gran auge en el mercado editorial español desde finales de los años ochenta, por la necesidad de cubrir 
cuestiones como el racismo, la inmigración, las relaciones interculturales e interreligiosas o la segunda generación, temas todos ellos de interés social, con repercusiones en el sistema educativo y en los medios de comunicación. Desde este planteamiento, el presente estudio presenta las normas preliminares de traducción de este tipo de LIJ, definidas a partir de un estudio de corpus formado por 150 obras publicadas en España con esta temática. En segundo lugar, se analizan las interacciones del polisistema literario español con otros polisistemas occidentales, en el marco del sistema literario mundial (Heilbron y Sapiro 2007). Por último, se aborda el papel de las editoriales españolas como parte del mecenazgo (Lefevere 1997), y su función en la conservación/ renovación de la poética del polisistema literario meta y en la construcción de la Otredad en la cultura española.

Palabras clave: LIJ; traducción; cultura arabo-islámica; polisistemas; editoriales; normas preliminares.

\begin{abstract}
From the point of view of both Postcolonial Studies and Manipulation School (Kruger 2012), children and young adult translated literature constitute a suitable field of analysis to study the construction of Otherness in contemporary societies, particularly as far as cultural minorities are concerned. It is because the relations between cultures are not neutral, nor are communicative exchanges; there are power relationships, and translation, as a shaping force on sociocultural structures (Venuti 1998), is not excluded from this situation, nor «innocent» (Lefevere \& Bassnett, 1990).

Accordingly, children's and YA literature of Arabic and Muslim issues had great success in the Spanish publishing market since the late 80', due to the need to discuss issues such as racism, immigration, intercultural and interreligious relations, and secondgeneration immigrants, current topics of highest social interest, with critical impact on both the Spanish education system and the media. From this approach, this study presents the preliminary norms for translation of this type of children's and YA literature, based on a corpus of 150 books published in Spain. Secondly, the interactions of the Spanish literary polysystem with other western polysystems are analysed, within the framework of the world literary system (Heilbron and Sapiro 2007). Finally, the role of Spanish publishers as part of patronage (Lefevere 1997), and their role in the conservation / renewal of the poetics of the target literary polysystem and in the construction of otherness in Spanish culture is addressed.
\end{abstract}

Key words: Children's \& YA literature; translation; Arab \& Islamic culture; polysystems; publishers; preliminary norms.

\title{
1. INTRODUCCIÓN
}

En un contexto postcolonial en el que están emergiendo nuevos actores con un bagaje cultural y lingüístico complejo, esta investigación aborda el papel de la

Beatriz SOTO ARANDA

Traducir literatura infantil y juvenil de temática árabe e islámica al castellano: editoriales, normas preliminares y polisistemas literarios en contacto
CLINA

vol. 5-1, June 2019, 113-130

elSSN: 2444-1961

Ediciones Universidad de Salamanca - CC BY-NC-ND 
traducción en la construcción del canon de la LIJ española contemporánea y los modelos culturales que esta representa y sanciona. En particular, se centra en la traducción de libros de temática árabe e islámica por dos razones: a) el Otro se identifica socialmente con la cultura de uno de los grupos de población inmigrada más importantes en España desde finales de los años ochenta, el de la población árabe, y más en concreto la marroquí, con una destacada presencia en el sistema educativo, y b) la relación de la cultura española con su pasado arabo-islámico es un tema que en la actualidad aún sigue produciendo controversias de carácter intelectual (Maillo 2004, Rodríguez Magda 2008), mediático (El-Madkouri y Soto Aranda 2018) y político (Stearns 2009). En este sentido, los estudios de traducción contemporáneos constituyen un campo de análisis idóneo para abordar la construcción del Otredad en las sociedades contemporáneas, particularmente por lo que a las minorías culturales se refiere, pues las relaciones entre culturas no son neutrales, como tampoco los intercambios comunicativos; existen relaciones de poder, y la traducción, como una fuerza conformadora de la cultura, ejerce un enorme poder en la construcción de representaciones de culturas extranjeras (Venuti 1998, 67-68).

En este contexto, resulta aún más relevante el análisis del corpus constituido por las obras que integran la Guía Simsim de libros infantiles y juveniles para asomarse al mundo árabe (en adelante Simsim), editada por Casa Árabe en 2008 y reeditada en 2010 (Soto Aranda 2017a), pues es un ejemplo claro del concepto de mecenazgo desarrollado por Lefevere, entendido este "como algo similar a los poderes (personas, instituciones) que pueden impulsar o dificultar la lectura, escritura y reescritura de la literatura)» (Lefevere 1997, 29), incluyendo la traducción. Esta guía constituye la primera recopilación realizada por una institución oficial de textos de LIJ publicados en España y disponibles en las librerías, que tratan aspectos relacionados con el mundo árabe. En la presentación de la edición de 2008, los editores de Simsim señalan que su finalidad principal es la de visibilizar este tipo de LIJ. Al respecto, Simsim planteaba en su presentación una situación asimétrica: por un lado, otros contextos internacionales, donde la publicación de libros de autores árabes y del mundo árabe es más habitual; y por otro, el caso de España, donde además de no publicarse, los pocos que existen están invisibilizados.

La lectura es una de las principales fuentes de aprendizaje. Esta es una invitación a asomarse a la diversidad del mundo árabe a través de los libros. En castellano no se editan tantos libros de autores árabes y del mundo árabe como en otras lenguas internacionales. Sin embargo, el auténtico problema es que los que existen suelen pasan desapercibidos. Por eso Casa Árabe hace esta guía de lectura: para contribuir a que se conozcan, se valoren y se disfruten. Como cualquier guía da pistas y sugiere caminos; le toca al lector recorrerlos: tirar del hilo que se le ofrece, hojear y descubrir lo que estos libros encierran.

Beatriz SOTO ARANDA

Traducir literatura infantil y juvenil de temática árabe e islámica al castellano: editoriales, normas preliminares y polisistemas literarios en contacto
CLINA

vol. 5-1, June 2019, 113-130

elSSN: 2444-1961

Ediciones Universidad de Salamanca - CC BY-NC-ND 
Sin embargo, en la edición de la guía 2010-2011 ya no se habla de autores árabes, centrándose en la visión sobre el mundo árabe, una suerte de aproximación imaginativa a través de la literatura. En concreto se puede leer: "esta guía es una invitación a asomarse a la diversidad del mundo árabe a través de los libros, a adentrarse, ver de cerca y valorar un universo cultural diferente y próximo a la vez». Este cambio de presentación está plenamente justificado por el contenido real de Simsim. Los textos traducidos del árabe o escritos en árabe (ediciones bilingües) son meramente testimoniales, correspondiendo a libros recomendados para primeros lectores y a aquellos de hasta nueve años. Para estas franjas de edad que corresponden básicamente con la educación infantil y la educación primaria también hay obras de autores árabes residentes principalmente en el Magreb cuyos textos han sido traducidos del francés. Asimismo, encontramos profusión de adaptaciones de obras clásicas como Las mil y una noches.

Por el contrario, Simsim está formada fundamentalmente por literatura autóctona y por obras traducidas del inglés, del alemán, del francés, del italiano y del catalán al castellano principalmente. Se trata de libros orientados sobre todo a los preadolescentes (entre nueve y once años) y a los adolescentes (doce años en adelante) y entre las obras reseñadas sí aparecen traducciones de autores con nombres árabes, pero que se han formado literariamente y escriben en países occidentales, luego no pueden ser considerados como representantes de la literatura árabe. A ello cabe añadir la inclusión de obras bilingües escritas originalmente en una lengua peninsular y traducidas al árabe. La LIJ traducida interactúa con la LIJ autóctona, de ahí que consideremos necesario comparar ambas para ver qué aportan las traducciones al polisistema literario meta. Como señala Wolf $(2000,129)$, «más que revisar estas dicotomías, cabe "deconstruirlas» analizando los complejos procesos involucrados en el contacto cultural y sus diversas implicaciones, y enfatizando el concepto de «diferencia» en la formación de la identidad cultural».

\section{POLISISTEMAS EN CONTACTO EN EL MARCO DE LA LIJ DE TEMÁTICA ÁRABE E ISLÁMICA}

La Guía Simsim está formada por 150 libros divididos en tres categorías lingüísticas: obras escritas en castellano (38.66 \%), obras bilingües (6.66 \%) y traducciones (54.66 \%) procedentes de diversos polisistemas. Las obras bilingües tienen como origen tanto el propio sistema castellano (44.4\%) como el sistema catalán (55.5\%), siendo que la presencia del árabe fusha se explica en la práctica totalidad de los casos por un proceso de retrotraducción de un texto escrito originalmente en catalán o en castellano que emula la lengua del Otro en un marco ideológico de reconocimiento de la Otredad interna, aquella que se identifica con la inmigración, pero también con

Beatriz SOTO ARANDA

Traducir literatura infantil y juvenil de temática árabe e islámica al castellano: editoriales, normas preliminares y polisistemas literarios en contacto 
el ensalzamiento de la diversidad lingüística y de la sociedad intercultural. Asimismo, la traducción permite la interacción del polisistema castellano con otras lenguas: el francés (32.92\% de los libros traducidos), el inglés (19.51\% de los libros traducidos), el alemán (13.41\% de los libros traducidos), el italiano (7.31\% de los libros traducidos), el neerlandés (2.43\% de los libros traducidos), el árabe -variedades dialectales hassania, marroquí y palestina- (3.65\% de los libros traducidos), el portugués (1.17 $\%$ de los libros traducidos) y el hebreo (1.17 \% de los libros traducidos). Y a través de ellas con diversos sistemas culturales occidentales: el francés, el estadounidense, el australiano, el inglés, el alemán, el belga, el holandés, el italiano y el brasileño, además del israelí. La presencia de estas lenguas y los polisistemas relacionados con ellas se encuentra estratificada en lenguas centrales, semiperiféricas y periféricas, en un orden que coincide con los hallazgos de investigaciones desarrolladas en el ámbito de la sociología de la traducción en los últimos años. Así, Heilbron y Sapiro (2007) concluyen que, en el marco de los intercambios literarios transnacionales, el inglés, el francés y el alemán funcionan como lenguas centrales; el español y el italiano como lenguas semiperiféricas, mientras que el árabe y el chino son lenguas periféricas. En el corpus analizado, la lengua central con diferencia es el francés, seguida del inglés, del alemán, del neerlandés, del italiano, del árabe y del portugués.

Junto a ello, también se da la traducción dentro de la comunidad interliteraria específica (CIE) española ${ }^{1}(16.25 \%$ del total), siendo que los polisistemas literarios pertenecientes a la CIE española ejercen la función de agentes renovadores de la poética del polisistema castellano, al permitir la presencia de nuevos actores en el ámbito de la traducción: a) autores traducidos desde los polisistemas de partida, es el caso de la escritora marroquí Sonia Ouajjou -aunque la autora publica en francés y en una coproducción con una editorial francesa-; b) la traducción desde editoriales de culturas periféricas; y c) autores de origen árabe que residen en Occidente. En unos casos, se trata de autores nacidos en países occidentales o que llegaron a Occidente en su infancia (p. ej. Randa Ghazy, Najat Hachmi y Laila Karrouch), que forman parte de la segunda generación de inmigrantes²; en otros, de autores que se trasladaron a vivir a Occidente siendo ya adultos y que se han dado a conocer literariamente en Occidente (p. ej. Amin Maalouf y Selim Alaflenish).

1. En la literatura científica relacionada con la LIJ y en especial en el ámbito de la traducción, se ha consolidado el término $\mathrm{CIE}$, con el que se designa a la Comunidad Interliteraria Específica española. Según Domínguez Pérez (2008, 4), las CIES se definen como «unidades históricas en las que varias literaturas se relacionan entre sí de una manera especialmente intensa y directa». La CIE española incluye las publicaciones de los polisistemas literarios vasco, catalán, valenciano, y gallego, además del referido a la lengua española.

2. Se trata de una denominación genérica utilizada para referirse a descendientes de inmigrantes. En el caso de países como España e Italia, hasta la fecha suele coincidir con hijos de la primera generación de inmigrantes árabes.

Beatriz SOTO ARANDA

Traducir literatura infantil y juvenil de temática árabe e islámica al castellano: editoriales, normas preliminares y polisistemas literarios en contacto
CLINA

vol. 5-1, June 2019, 113-130

elSSN: 2444-1961

Ediciones Universidad de Salamanca - CC BY-NC-ND 
Mención especial merecen editoriales valencianas y catalanas que publican en castellano, al trasvasar al polisistema castellano una sensibilidad lingüística hacia el Otro, visibilizando la escritura árabe en textos infantiles bilingües. Este hecho constituye una novedad en el ámbito de la LIJ en castellano, pues permite que una de las señas de identidad de la cultura árabe emerja ante el lector, a la vez que reconoce la existencia de posibles lectores con bagajes lingüísticos y culturales distintos al monolingüismo. A su vez, se han concebido como recursos para apoyar la enseñanza de las lenguas de la inmigración en el ámbito educativo a edades tempranas. Así, la editorial valenciana Ecir ha editado Hamza y El gigante Herkel, obra de S. Muhammad y S. Abdelhadi, una recreación del mito de Hércules que recuerda las grutas de Hércules en Tánger; y El sacrificio de Morad, de Nadia Daoud BrikciAimeur, una historia familiar ambientada en Argelia. En el caso de las editoriales catalanas, Marge Books publica en sendas ediciones digitales bilingües (español árabe y catalán árabe) la obra Cuentos de Bagdad, de Gloria Arimon, contra el embargo decretado a Iraq en 2002. De la presentación de la obra, se deriva un interés por plantear una crítica a las situaciones bélicas desde una perspectiva ética:

Como en los relatos de Las mil y una noches, estos cuentos quieren demostrar que la palabra y la razón son las mejores armas contra la barbarie y la guerra. Realidad y fantasía unidas para recuperar esperanzas perdidas, ilusiones enterradas bajo los pozos de petróleo, miradas de chicos y chicas que quieren un presente en paz.

Por último, la editorial catalana La Galera publica dos obras de Anna Molins: Yoha y el hombre de la ciudad/El chico y los animales y El filósofo y el pescador/La anciana y los mosquitos, basadas en cuentos tradicionales árabes, cuya traducción ha corrido a cargo de Tànit Assaf Muntané. Ambas obras son ejemplos de retrotraducciones, un fenómeno llamativo dentro de la LIJ, al que se recurre para producir publicaciones de apoyo al aprendizaje de la lengua de acogida como $L^{2} \mathrm{O}$, como parece el caso, en apoyo a la interculturalidad y al reconocimiento de otros bagajes lingüísticos en los lectores. De este modo, una historia tradicional del acervo cultural de origen es rescrita en la lengua meta y traducida de nuevo a la lengua de partida.

Igualmente, resalta la agencia de editoriales valencianas y catalanas como intermediarias en la incorporación al polisistema literario castellano de obras escritas originalmente en euskera. Así, Pies sucios de Koldo Izagirre fue publicada por la barcelonesa Takatuka. No soy rubia, del escritor Kirmen Uribe, se incorpora a través de la barcelonesa La Galera, y Arroz y tinta, de Patxi Zubizarreta, a través de la valenciana Algar.

Beatriz SOTO ARANDA

Traducir literatura infantil y juvenil de temática árabe e islámica al castellano: editoriales, normas preliminares y polisistemas literarios en contacto
CLINA

vol. 5-1, June 2019, 113-130

elSSN: 2444-1961

Ediciones Universidad de Salamanca - CC BY-NC-ND 


\section{NORMAS PRELIMINARES PARA LA TRADUCCIÓN DE LIJ DE TEMÁTICA ÁRABE E ISLÁMICA}

Una asunción fundamental de los estudios de traducción actuales es que las traducciones forman parte de la cultura meta y constituyen una forma de comportamiento social, regido por normas (Koster 2010, 22). En este sentido, Wolf (2007a, 1) plantea cómo la función social de la traducción y su valor socio-comunicativo se vislumbra en la zona de encuentro entre el texto traducido y las diversas agencias sostenidas por la sociedad. Los textos traducidos -concebidos como discursos culturales-, su contenido y la forma de presentarlo, se insertan en el polisistema meta, siendo su adecuación a las normas imperantes en este lo que marca su publicación; para Faiq $(2004,35)$ «este sistema envuelve un «discurso principal» a través del cual se identifican identidad, similitud y diferencia, se negocian, se aceptan, y / o se resisten». Como señala Carbonell $(1998,223)$ :

Cuando se trata de obras de culturas alejadas las estrategias de selección que están en juego aparecen mucho más claras. La aceptabilidad está relacionada con factores ideológicos y, aunque las editoriales jueguen un papel crucial a la hora de definir los gustos del público en general, es difícil que una obra se traduzca si no entra dentro de una tendencia o moda ya establecida.

No debe olvidarse, además, que, junto a su función lúdica, este tipo de literatura tiene una finalidad didáctica notoria, máxime en una edad en la que se configura la identidad personal y colectiva de los lectores. Cabe asumir, pues, que el lector meta accede a ella mediatizado por el sistema educativo y por la familia, además de por las valoraciones críticas de los medios de comunicación e internet. De ahí que estudiar la LIJ permite aproximarnos a los valores que imperan en nuestra sociedad. En este sentido, podemos considerar que las editoriales dedicadas a la LIJ habitualmente se guían por estos principios a la hora de decidir la publicación o no de una obra, ya sea autóctona o traducida. Desde esta perspectiva, la comparación de libros escritos en castellano y los traducidos nos han permitido trazar un mapa inicial de las normas preliminares que funcionan en la incorporación de obras que versan sobre la cultura árabe e islámica al en el marco de la $\mathrm{LIJ}^{3}$.

3. Si bien las normas se circunscriben al corpus analizado, la amplitud del mismo y el hecho de que el corpus no sea una selección personal nuestra, sino que formen parte de una guía de consulta publicada por una institución oficial como Casa Árabe, permite plantear la hipótesis de que dichas normas puedan regir el conjunto de las obras de LIJ de esta temática. Por supuesto, será necesario ampliar el período de estudio hasta la actualidad, incluyendo todas las obras que han visto la luz con posterioridad a la publicación de Simsim.

Beatriz SOTO ARANDA

Traducir literatura infantil y juvenil de temática árabe e islámica al castellano: editoriales, normas preliminares y polisistemas literarios en contacto
CLINA

vol. 5-1, June 2019, 113-130

elSSN: 2444-1961

Ediciones Universidad de Salamanca - CC BY-NC-ND 
1. En primer lugar, interesan cuentos y álbumes ilustrados que hablen de las culturas magrebíes, la Otredad geográficamente más cercana a la Península, junto con las del Sahara. Al respecto, cabe señalar que la cuestión saharaui, presente en la LIJ en el marco de la CIE española (6 \% del corpus), no aparece en otras LIJ occidentales. En el marco de las culturas del Magreb, las editoriales otorgan una destacada importancia a la cultura bereber, particularmente en el ámbito del polisistema gallego.

2. La cuestión palestina, tema tratado por autores árabes como Ghazi Abdel-Qadir, perteneciente al polisistema alemán, e Ibtisam Barakat, escritora palestina afincada en los EE. UU, junto con Valerie Zenatti (Francia), Daniela Carmi (Israel), Paola Zanonen (Italia) y la autora franco belga Litsa Boudalika. Asimismo, destacan las obras que Joe Sacco ha dedicado al tema en formato cómic. La orientación y representatividad de las obras varía en función del tipo de editorial responsable de la publicación, apreciándose dos tendencias editoriales: una que apuesta por una solución negociada y pacífica al conflicto y otra que da voz a posiciones pro palestinas, siempre que vayan avaladas por la crítica y las ventas en el mercado internacional.

3. Se observa una especial sensibilidad hacia las repercusiones sociales de los conflictos bélicos con obras como La bibliotecaria de Basora, de Jeanette Winter, basada en una historia real que tiene como trasfondo la guerra de Iraq. A este grupo de obras cabe añadir el ciclo de cómics dedicado a la guerra civil libanesa con $\mathrm{Me}$ acuerdo: Beirut y El juego de las golondrinas, dos aproximaciones autobiográficas de la escritora libanesa Zina Abirrached, junto con La chica del pelo corto, de la escritora francesa de origen libanés Kochka.

4. Al-Ándalus constituye otro de los temas centrales de la guía, avalado por figuras destacadas de la LIJ en castellano como Luis del Corral y M. ${ }^{a}$ Isabel Molina, quienes comparten protagonismo con autores extranjeros como Amin Maalouf con León el Africano y Ann Jungmal con La mezquita maravillosa. Maalouf recrea la vida de un personaje, Hasan Bin Muhammad al-Wazzan al-Fas, más conocido como León el Africano, quien debió de nacer en Granada hacia1488. El protagonista realiza un periplo que lo llevará a Tombuctú y a Oriente, y trabajará a las órdenes de papa León $X$ y de Julio de Médicis. León el Africano quizá sea uno de esos personajes históricos que mejor recrean la ambivalencia de la que hablan autores como Bhabha, y la noción de identidad líquida de Bauman trasladadas al siglo XV. Así lo define José María Ridao cuando afirma que:

La elección de un personaje [...] evidencia el propósito de situar la narración en una de las numerosas páginas en blanco, de los múltiples recovecos y oquedades, que ofrece la historia del Mediterráneo durante el periodo más dramático del enfrentamiento entre el Imperio Otomano y la cristiandad [...].

Beatriz SOTO ARANDA

Traducir literatura infantil y juvenil de temática árabe e islámica al castellano: editoriales, normas preliminares y polisistemas literarios en contacto
CLINA

vol. 5-1, June 2019, 113-130

elSSN: 2444-1961

Ediciones Universidad de Salamanca - CC BY-NC-ND 
Maalouf adopta la voz de un personaje histórico, que es sin embargo su personaje, para recordar que las fronteras son contingentes, tanto entre los individuos como entre los territorios (El País, «León el Africano, hombre de frontera», 18/09/2005).

Sin embargo, frente al planteamiento que propone el autor, la editorial Alianza resalta el hecho del nacimiento del protagonista en Granada, equiparando el concepto de «andalusí» al de «andaluz» en la contraportada de la obra: «un hombre nacido en Granada poco antes de la caída de la ciudad en manos cristianas vivirá una aventura extraordinaria uniendo en su experiencia Oriente y Occidente, el mundo cristiano y el islam. Exiliado en Fez como tantos árabes andaluces [...]». Esta información sirve de filtro para su incorporación al polisistema meta, si bien no aparece en la nota ofrecida por Le libre de poche, editora de la versión original francesa, que tan solo indica que "se encontraba en Granada durante la Reconquista, de donde debe huir de la Inquisición con su familia».

Igualmente, en el corpus está presente la mirada romántica de Las leyendas de la Alhambra de Washington Irving, con el cuento de El astrólogo y la hechicera, una traducción-adaptación de la editorial gallega $\mathrm{OQO}$, en la que se fantasea sobre el lugar donde se debió de levantar la Alhambra, espacio que escogió para asentarse un sabio astrólogo a las órdenes de un rey árabe, Aben Habuz. Así, la norma preliminar con relación a este tema parece estar orientada a la aceptación de obras que resalten la convivencia de las tres culturas, junto al cuestionamiento de la identidad.

5. La inmigración. Esta temática aparece a finales de los ochenta, coincidiendo con la incorporación de España al mapa de los flujos migratorios internacionales. Se ha tratado desde dos perspectivas complementarias: a) el racismo, la primera obra traducida al castellano, Anne aquí, Selma allí, se publicó en 1986 procedente del polisistema francés; y b) la progresiva incorporación de población de origen inmigrante al sistema educativo español conlleva un interés por la cuestión de la identidad y las diferencias culturales. La práctica ausencia de obras que abordaran esta temática en la LIJ en castellano lleva a la editorial Edelvives a publicar en 2001 Al otro lado del Estrecho, de la escritora belga marroquí Nicole Boumaaza.

6. La Otredad en femenino. La literatura de reivindicación es uno de los ejes de esta LIJ. Las obras incorporadas al polisistema castellano desde otras lenguas, como el inglés con Sueños en el umbral. Memorias de una niña del harén ${ }^{4}$ de la escritora marroquí Fatima Mernissi, y Diez cosas que odio de mí y ¿Por qué todos me miran la cabeza?, de la escritora australiana de origen egipcio palestino Randa Abdel-Fattah,

4. Formalmente, no parece que la obra esté pensada para lectores infantiles ni juveniles, por lo que considero que stricto sensu no pertenece a la LIJ, aunque Simsim sí la incluye, quizá porque en el título aparece el término «niña» y por el prestigio de la autora, ganadora del premio Príncipe de Asturias de las Letras en 2003.

Beatriz SOTO ARANDA

Traducir literatura infantil y juvenil de temática árabe e islámica al castellano: editoriales, normas preliminares y polisistemas literarios en contacto
CLINA

vol. 5-1, June 2019, 113-130

elSSN: 2444-1961

Ediciones Universidad de Salamanca - CC BY-NC-ND 
el catalán con Leila de Leila Karrouch y el italiano con Hoy no voy a matar a nadie de la escritora italiana de origen egipcio Randa Ghazy, muestran el interés del polisistema meta por la voz femenina, aunque para su incorporación las obras hayan de venir avaladas por el sistema literario de partida y por premios internacionales, mientras que la recepción de las mismas y su aceptación dependan del proceso de legitimación realizado por las editoriales a través de la información paratextual.

Ya se trate de escritoras residentes en países árabes como Mernissi, o pertenecientes a la segunda generación, como Abdel-Fattah o Ghazy, su escritura se caracteriza por un intento consciente de ruptura de los estereotipos que existen sobre la cultura árabe en las sociedades occidentales, a cuyos polisistemas pertenecen realmente sus obras. Así, por ejemplo, Sueños en el Umbral, memorias de una niña del harén, relata en forma de autobiografía novelada -uno de los formatos que Vega (2003) señala como prototípicos de la literatura postcolonial- la infancia de Mernissi en un marco cultural propio de la clase media alta de Fez: un edificio construido en torno a un patio en el que vivía la familia extensa: abuelos, padres, hijos, primos, etc., que llevaba por nombre harén. Se observa aquí una escritura de resistencia en la que términos culturalmente marcados en la cultura de destino como «harén» resultan reinscritos mediante un proceso de resignificación: el harén de las concubinas, espacio inmortalizado por los pintores y escritores europeos, asume uno de sus significados originales en las culturas de partida: un espacio físico familiar. A su vez, Mernissi intercala la oralidad, aunque sea una oralidad literariamente construida, a través de las historias de Las mil y una noches, también con un propósito de resistencia: reinscribir la figura de Shahrazad como se interpreta en el mundo árabe. Como dice Mernissi en una nota a pie de página:

Me sorprendió comprobar que muchos occidentales consideraban a Shahrazad una animadora encantadora pero simple, alguien que cuenta historias inocuas y viste de manera fabulosa. En nuestra región del mundo vemos a Shahrazad como una heroína valerosa y es una de nuestros escasos personajes míticos (Mernissi 1994, 26).

El receptor meta de esta obra no es un lector árabe; por el contrario, obras como estas están pensadas para desempeñar la función de mediación cultural en contextos de recepción occidentales. Cabe recordar al respecto que Mernissi publica la mayor parte de su obra en EE. UU. y en Francia para un lector claramente occidental, como mostraba ya su primera obra Beyond the Veil: Male-Female Dynamics in Modern Muslim Society, fruto de su tesis doctoral en Sociología (University of Brendeis, 1975), en la que inserta una «nota para el lector occidental». El papel de mediación se ejerce recurriendo a diversas estrategias que suelen caracterizar la traducción cultural (Carbonell 2003), como son notas a pie de página bastante extensas (todas ellas reproducidas en la traducción al castellano), con una función informativa, prototípicas de las traducciones académicas:

Beatriz SOTO ARANDA

Traducir literatura infantil y juvenil de temática árabe e islámica al castellano: editoriales, normas preliminares y polisistemas literarios en contacto
CLINA

vol. 5-1, June 2019, 113-130

elSSN: 2444-1961

Ediciones Universidad de Salamanca - CC BY-NC-ND 
Harén. Quizá sea oportuno establecer ahora una distinción entre dos tipos de harenes: llamaremos a los primeros «harenes imperiales», y «harenes domésticos» a los segundos. (...) Llamaremos «harenes domésticos» a los que siguieron existiendo después de 1909, cuando los musulmanes perdieron el poder y sus territorios fueron ocupados y colonizados. Los «harenes domésticos» en realidad eran familias ampliadas... son bastante aburridos, por su marcado carácter burgués (...) (Mernissi 1994, 47-48).

Junto a ellas, aparecen otras notas con referencias bibliográficas complementarias, en idiomas europeos cuando existen, y en árabe cuando las considera relevantes y no están traducidas a otros idiomas potencialmente accesibles al lector meta. A su vez, recurre a la glosa explicativa para explicar términos propios de la cultura de partida. Un ejemplo de nota es el siguiente: «Renunciarían gustosamente a su plan si Lalla Thor les enseñaba una fatwa, un decreto de las autoridades religiosas de la mezquita Qraouine que prohibiera a las mujeres fregar los cacharros en el río» (Mernissi 1994, 87).

Las escritoras árabes se encuentran así en un territorio in-between, liminar en palabras del escritor marroquí Al-Khatabi, desde el que tienen que hacer frente a posturas orientalistas y eurocéntricas sobre el mundo árabe, por un lado, y mostrar sus opiniones sobre la situación de la mujer en el mundo árabe, por otro. Al utilizar lenguas europeas no solo apelan a audiencias globales más amplias, sino que pueden trabajar fuera de las convenciones y parámetros culturales (Merhrez 1992, 121-122), convirtiéndose en una suerte de mediadoras, de «informantes nativas», de traductoras en un sentido metafórico utilizado por la antropología contemporánea (Geertz 1973) y por estudiosos como Bhabha (1990), Friedman (1998) y Glisant (1990), que traducen sus culturas de partida a las culturas meta, convirtiéndose sus discursos en textos de partida susceptibles de ser analizados por haber sido reconocidos por la cultura meta que es a la vez cultura de partida, como representativos y legítimos (Sturge 2007).

Sin embargo, y a pesar de que la editorial Muchnik realiza una traducción íntegra de la obra que incluye las notas a pie de página y las glosas, también recurre a la información paratextual para acomodar el libro al marco cultural meta y a la visión estereotipada del mundo árabe. Así, en la portada de la obra aparece una mujer velada que reproduce visiones arquetípicas de la mujer árabe, mientras que en la contraportada se conecta la obra con un mundo de visiones orientalistas, entre otras: a) los cuentos de Las mil y una noches y la seducción femenina: «En un libro con el poder evocativo de Las mil y una noches... Con el poder de encantamiento de las fábulas y la fuerza narrativa de las historias realmente vividas»; b) La seducción y la sensualidad femeninas (evocación de Shehrazade): "Mernissi escribe sobre las estrategias de la seducción...", "Unas memorias provocativas, habitadas por mujeres individualistas, divertidas, sabias y maravillosas que recompensan a su lector con el placer de la inteligencia y la frescura.

7. La recreación de Oriente. La norma preliminar parece establecer una relación estrecha entre la representación icónica de esta cultura y los cuentos tradicionales,

Beatriz SOTO ARANDA

Traducir literatura infantil y juvenil de temática árabe e islámica al castellano: editoriales, normas preliminares y polisistemas literarios en contacto
CLINA

vol. 5-1, June 2019, 113-130

elSSN: 2444-1961

Ediciones Universidad de Salamanca - CC BY-NC-ND 
especialmente los de tradición oral, ambientados en marcos culturales muy restringidos, como es el desierto, en consonancia con los postulados de Edward Said en Orientalismo. Un ejemplo es la traducción de El camello de hojalata, del escritor palestino afincado en Alemania Ghazi Abdel-Qadir. Él utiliza un género literario, el de las narraciones exotizantes, que resulta aceptable en el polisistema de partida, donde también se da esta norma preliminar (Berman 2011, Pino Valero 2010), norma que se ve reforzada con el uso del término camello en el título, aunque aquí su uso sea metafórico. Sin embargo, el texto esconde en realidad una finalidad de crítica medioambiental que, aunque señalada en la contraportada de la obra traducida, queda diluida en detrimento de la norma preliminar al aparecer dibujado el camello en la portada. Pero también existe una imagen estereotipada del árabe, reflejada en obras como Tintín y el oro negro, de una clara inspiración colonial, pero que habitualmente no son rechazadas por el lector, aunque sí por la crítica especializada (López García 2007), al resultar homologables con las imágenes que las sociedades occidentales postmodernas, a través del cine o de los videojuegos, reflejan de otras sociedades y culturas como la arabo-islámica. La existencia de este tipo de obras también muestra la pertinencia de las críticas de autores como Said, Ahmad, Faiq, Carbonell o Selim sobre el exotismo de la estereotipación cultural en el marco de los estudios de traducción (Soto Aranda 2018).

8. Las adaptaciones/versiones de Las mil y una noches. Estas constituyen un $4 \%$ del total del corpus, aunque el porcentaje es menor del que cabría imaginar a priori. Sin embargo, la presencia de autores árabes refuerza corrientes de cuentística fantástica y sobrenatural de moda en la LIJ actual, que funcionan como alternativa al prototipo de Las mil y una noches canonizadas en Occidente: es el caso del Cuento de los contadores de cuentos del tunecino Nacer Khemir o Simbad el Terrestre de René Khawan. Junto a ello, los personajes protagonistas de muchas historias del acervo cultural árabe como Yoha o Nasrudin se incorporan al polisistema literario castellano de la mano de autoras occidentales como Odie Weulerss o Anna Molins,

9. La legitimación internacional. Editoriales como Bambú, Edelvives y La Galera se aventuran con la traducción de narrativa de autoras procedentes del polisistema australiano, estadounidense o italiano, tales como Randa Ghazy, Ibtisam Barakat o Randa Abdel-Fattah. Narrativas, las de las tres, en las que se plantean tanto la xenofobia social como el cuestionamiento de la identidad como un hecho individual o las diferencias culturales entre las sociedades de origen y las de acogida. Esta nueva realidad es fruto de un interés concreto de las editoriales, pero también del éxito alcanzado por las obras en su país de origen o en otro país europeo, especialmente Francia o Gran Bretaña, los premios conseguidos por la obra original y los intercambios editoriales que se producen en las ferias internacionales, determinantes de la selección y traducción de textos dirigidos a un público infantil y juvenil. Se puede concluir que, junto a los intereses comerciales, las editoriales también desempeñan una función ideológica significativa en la selección de obras y autores, en la configuración de la poética y del polisistema literario.

Beatriz SOTO ARANDA Traducir literatura infantil y juvenil de temática árabe e islámica al castellano: editoriales, normas preliminares y polisistemas literarios en contacto 
10. La no traducción del árabe fusha al castellano. Simsim no contiene ningún libro que se haya traducido directamente del árabe fusha al castellano, hecho que coincide con otros hallazgos realizados por Heilbron y Sapiro (2007), para quienes el árabe, a pesar de ser una de las lenguas más habladas del mundo, es una lengua con escaso prestigio internacional y poco capital simbólico, teniendo en cuenta que Bourdieu señala que el capital cultural se convierte en simbólico no por el valor real de dicho capital, sino por el valor que otorgan otros agentes en el marco de la cultura. Así, la traducción de una lengua periférica como el árabe a una lengua semiperiférica como el castellano, en el ámbito de los intercambios literarios internacionales, ha de pasar por una lengua intermedia, una lengua central del sistema transnacional, que en el caso de la LIJ de temática árabe e islámica es el francés, que legitime dicha publicación. En este caso, la función del francés es especialmente relevante por lo que a los autores de origen árabe se refiere, tal y como ha mostrado recientemente Pickford (2016), pues el polisistema francés se concibe como una puerta de entrada al sistema literario transnacional, una suerte de legitimación, por un lado; por otro, el polisistema francés tiende a no traducir del árabe, salvo determinadas editoriales, favoreciendo la publicación de obras de autores árabes en francés (Jacquemond 1992).

Las editoriales prefieren sustituir la traducción directa del árabe fusha por: a) la traducción de literatura producida en árabe dialectal, y b) la traducción de literatura producida por autores de origen árabe que han publicado directamente en uno de los polisistemas literarios centrales. De ahí que se pueda afirmar que la asimetría entre lenguas y culturas es un hecho en este ámbito de la traducción (Carbonell 1996, 81). La traducción directa del árabe dialectal se produce por la agencia de traductores españoles que presentan un proyecto de reconocimiento, que puede incluirse dentro de la literatura de resistencia y de defensa de la identidad cultural en el marco de la literatura postcolonial, de diferentes marcos culturales y sociales que conforman el mundo árabe e islámico: es el caso de Rosa Rabadán Carrascosa y su traducción de los cuentos de la jrefiyye palestina y de la traducción de la narrativa oral saharaui de la región de Trab el-bidan por Fernando Pinto Cebrián. Su publicación difícilmente se hubiera producido sin el apoyo de editoriales con un proyecto ético definido, como es el caso de Miraguano:

Desde los inicios de Miraguano Ediciones en 1978 me propuse prestar una especial atención a la difusión de las culturas populares (cuentos de tradición oral, leyendas, costumbres, etc.) de pueblos y grupos étnicos poco conocidos en nuestro país, y en particular de los pueblos oprimidos, minoritarios o marginados cuyo acervo cultural corriera grave riesgo de desaparición por diferentes razones (aculturalidad, represión, etc.). Y en este contexto, siempre me ha interesado el pueblo saharaui, con el que España contrajo una ingrata deuda cuando el general Franco lo abandonó a su suerte (marroquí) en 1975. Contribuir a divulgar sus cuentos populares, sus proverbios o sus juguetes y juegos tradicionales para que, en la medida de lo posible y según nuestras

Beatriz SOTO ARANDA

Traducir literatura infantil y juvenil de temática árabe e islámica al castellano: editoriales, normas preliminares y polisistemas literarios en contacto
CLINA

vol. 5-1, June 2019, 113-130

elSSN: 2444-1961

Ediciones Universidad de Salamanca - CC BY-NC-ND 
humildes posibilidades, no cayeran en el olvido, me pareció casi una obligación editorial. En ese sentido, también figuran en nuestro catálogo otros volúmenes de cuentos tradicionales palestinos y bereberes, por ejemplo (José Javier Fuente del Pilar, editor, encuesta realizada el 16/10/2014).

Otras obras como Zelgum o Huevos duros, procedentes del polisistema literario gallego, reconocen la cultura beréber argelina, aunque la editorial las presenta como adaptaciones, no como traducciones.

Los autores árabes presentes a través de la LIJ se dividen en tres grupos. El primero corresponde a autores inmigrados a Occidente, es decir, que no han nacido en países occidentales, habiéndose incorporado a alguno de los polisistemas literarios occidentales tras un proceso migratorio (46.6 \%). Proceden de tres polisistemas: el alemán (Ghazi Abddel-Qadir (Palestina), Selim Alaflinesch (Jordania) y Rafik Schami (Siria)); el francés (Tahar Ben Jelloun (Marruecos), Amin Maalouf (Líbano), René Khawan (Siria) y Zina Abirrached (Líbano)) y el estadounidense, (Ibtisam Barakat (Palestina)). El segundo grupo es el de autores residentes en países árabes que publican en polisistemas occidentales, aunque tienen una relación académica/intelectual con determinados sistemas culturales occidentales (26.6 \%). Se han incorporado a través del polisistema estadounidense (Fatima Mernissi (Marruecos)) y del francés (Nacer Khemir (Túnez) y Moheddin Ellabad (Egipto)). El tercer grupo está formado por autores pertenecientes a la segunda generación de inmigrantes, es decir, autores que, o han nacido en países occidentales, o llegaron a ellos en su infancia y se han formado en ellos (26.6 \%). Forman parte del polisistema francés (Azouz Begag y Farid Boudjellal (Argelia)); del australiano (Randa Abdel-Fattah); y del polisistema italiano (Randa Ghazy).

La presencia de autores provenientes de las excolonias como es el caso de Argelia y Marruecos plantea la función social y cultural de las lenguas coloniales en los contextos postcoloniales, sus implicaciones ideológicas, identitarias y culturales, así como la agencia de las culturas metropolitanas en la consideración y configuración de la cultura y lengua árabe en el marco de los intercambios literarios transnacionales, máxime cuando en contextos como el norte de África, el árabe se constituyó en instrumento de resistencia frente al colonizador. En este contexto, la lengua y la traducción se visibilizan como instrumentos ideológicos, conformadores de la identidad de la cultura árabe e islámica en Occidente (Soto Aranda 2017).

\section{CONCLUSIONES}

El hecho de que en el sistema castellano exista una LIJ de temática árabe e islámica constata el interés de la sociedad española y de los diversos agentes conformadores de la cultura, como las editoriales, por el Otro: definirlo, abarcarlo, en definitiva,

Beatriz SOTO ARANDA

Traducir literatura infantil y juvenil de temática árabe e islámica al castellano: editoriales, normas preliminares y polisistemas literarios en contacto
CLINA

vol. 5-1, June 2019, 113-130

elSSN: 2444-1961

Ediciones Universidad de Salamanca - CC BY-NC-ND 
para entenderlo. La traducción de LIJ extranjera, así como la procedente de otras lenguas de la CIE española, es muestra del interés de las editoriales por dar respuesta a los retos a los que enfrenta la sociedad española en los últimos años, a la vez que dicha agencia tiene una destacada carga ideológica en la medida en que se selecciona a partir de planteamientos literarios, pero también éticos. Como dice Wolf (2007b, 118), la traducción, entendida como tercer espacio, está conformada por agentes, sujetos a continuas reinterpretaciones, que pueden cuestionar órdenes existentes y dejar abierto el potencial de múltiples contextualizaciones. Así, parafraseando a Fairclough y Wodak $(1997,241)$, las traducciones concebidas como discursos contribuyen a la construcción de la sociedad y de la cultura, son históricas - de ahí que los textos puedan volverse a traducir en función del interés que desee otorgarle la cultura meta, están condicionadas por las relaciones de poder; en suma, son una forma de acción social-. Ello sin olvidar que «la traducción que crea culturas minoritarias, crea simultáneamente identidades para ellas» (Venuti 1998, 138).

A pesar de la globalización, el Otro que interesa sigue siendo fundamentalmente el Otro interno, el que comparte espacio físico con la cultura meta: el inmigrante. La LIJ plantea la cuestión de la identidad de la segunda generación y las diferentes maneras de abordarla: asimilación, multiculturalismo, interculturalidad. Así, la lengua del Otro, en este caso el árabe, emerge gracias a la agencia de editoriales que apoyan el bilingüismo como política intercultural. Asimismo, la presencia de autores y autoras de origen árabe a través de la traducción muestra el interés por dar voz al Otro, pero un otro accesible a través de las lenguas que se hablan en Occidente, avalado por sistemas culturales centrales como el francés, el inglés o el alemán, por los premios internacionales o la buena acogida en otros mercados occidentales. En este sentido, la LIJ de temática árabe e islámica es deudora de las normas preliminares que funcionan en dichos sistemas, siendo que algunos de ellos como el francés aún desempeñan el rol de metrópolis culturales para sus ex colonias.

A través de la agencia de autores de segunda generación y de autores árabes residentes en los países de origen, en la LIJ en castellano se visibilizan historias y personajes que hablan de otras tradiciones o las reescriben, como el caso de Shehrazad de manos de Fatima Mernissi. Autores y autoras que juegan con la ambivalencia del mito de la leyenda oriental, como René Khawan o Selim Alaflenish, para inscribir otras historias, las huellas de un Otro que se distingue de nuestra construcción cultural. En el corpus analizado, la traducción de los cuentos de la jrifiyye palestina por Rosa Rabadán o las obras de Pinto Cebrián son ejemplos de su socavamiento de un cierto orden preestablecido por parte de los traductores; mientras que la traducción y publicación de las obras de Randa Abdel-Fattah, Ibtisam Barakat y Fatima Mernissi pueden considerarse como ejemplos rupturistas por parte de editoriales españolas.

El Otro, las otras, se visibilizan porque sus obras responden o coinciden al menos tangencialmente con intereses históricos, políticos, intelectuales o coyunturales

Beatriz SOTO ARANDA

Traducir literatura infantil y juvenil de temática árabe e islámica al castellano: editoriales, normas preliminares y polisistemas literarios en contacto 
localizados en los mercados de distribución literaria. Junto a ello, y como recuerda Mehrez (1992), es cierto que, al usar la lengua del colonizador, los escritores postcoloniales van más allá de una posición contestataria pasiva, «en la que el texto postcolonial permanece prisionero de los modelos literarios y estándares occidentales». Por el contrario, los autores postcoloniales «aspiran a subvertir tanto los modelos autóctonos tradicionales como las estructuras dominantes del colonizador con el fin de crear mutua interdependencia e intersignificación» (Gyasi 2006, 44). Sin embargo, el resultado final, la recepción del lector meta, no depende tanto de sus intenciones como de la agencia de la cultura meta.

Así, cabe finalizar constatando que las normas van más allá de ser simples procedimientos aplicables a las traducciones de forma regular para inscribirse en el marco de la ideología. Este es un término clave para entender la recepción de la literatura foránea en un polisistema meta determinado, y con ella, la conformación de la autoimagen y la imagen del Otro, y asumir que las diversas historias de la traducción y los debates que conllevan en el marco del estado-nación colonial o postcolonial «abren un espacio en el que resulta posible interrogar y cuestionar los discursos y las prácticas hegemónicas que han tejido este espacio, institucional y epistemológicamente» (Selim 2009, 3).

\section{BIBLIOGRAFÍA}

ABDEL-QADIR, Ghazi. 1998. El camello de hojalata. [orig. Das Blenchkamel]. Traducido por Rosa Pilar Blanco Santos. Madrid: Alfaguara.

BASSNETT, Susan y André LEFEVERE. 1990. Translations, History and Culture. London: Bloomsbury Academic.

BeRman, Nina. 2011. German literature on the Middle East. Discourses and Practices: 10001989. Michigan: The University of Michigan Press.

BHABHA, Homi. 1990. "The Third Space». En Identity: Community, Culture, Difference, ed. por Jonathan Rutherford. London: Lawrence \& Wishart, 207-221.

CARBONELL, Ovidi. 1996. "The Exotic Space of Cultural Translation». En Translation, Power, Subversion, ed. por Román Álvarez y África Vidal Claramonte. Clevedon: Multilingual Matters, 79-98.

CARBONELL, Ovidi. 2003. «La novedad entre dos mundos. Hacia una nueva teoría de la Otredad en traducción». En AIETI. Actas del I Congreso Internacional de AlETI, ed. por Ricardo Muñoz Martín. Granada: AIETI, 379-398. Acceso el 10 de abril de 2017. http://www.aieti. eu/wp-content/uploads/AIETI_1_OCC_Novedad.pdf

DOMínGUEZ PÉREZ, Marta. 2008. Las traducciones de la comunidad interliteraria específica española (1940-1980). Santiago: Universidad de Santiago de Compostela. Http://dspace. usc.es/bitstream/10347/2400/1/9788471914668_content.pdf

EL-MADKOURI, Mohamed y Beatriz SOTO ARANDA. 2018. «La metaforización del Otro en la traducción de sus construcciones lingüísticas en los Medios». En La identidad en el mundo

Beatriz SOTO ARANDA Traducir literatura infantil y juvenil de temática árabe e islámica al castellano: editoriales, normas preliminares y polisistemas literarios en contacto 
hispano. Igualdades y desigualdades en los siglos XIX, XX y XXI a través de diversos textos, ed. por Teresa Fernández de Ulloa. Vigo: Editorial Academia, 171-188.

EVEN-ZOHAR, Itamar. 1999. "La posición de la literatura traducida en el polisistema literario». En Teoría de los polisistemas, ed. por Montserrat Iglesias Santos Madrid: Arco Libros, 223-231.

FAIQ, Said. 2004. «The Discourse of Intercultural Translation». En Intercultural Communication Studies XIII: 3, 35-46.

FAIRCLOUGH, Norman y Ruth WODAK. 1997. "Critical discourse analysis». Discourse Studies. A multidisciplinary introduction, 2. Discourse as social interaction, ed. por Teun van Dijk. London: Sage, 258-284.

FriedMAN, Susan. 1998. Mappings. Feminism and the Cultural Geographies of Encounter. Princeton: Princeton University Press.

GEERTZ, Cliford. 1973. The interpretation of Cultures. New York: Basic Books.

GLISSANT, Éduard. 1990. Poétique de la Relation, Paris, Gallimard.

GYASI, Kwaku. 2006. The Francophone African text. Translation and the Postcolonial Experience. Nueva York: Peter Lang.

HEILBRON, Johan y Gisèle SAPIRO. 2007. «Outline for A Sociology of Translation. Current Issues and Future Prospects». En Constructing a Sociology of Translation, ed. por Michaela Wolf y Alexandra Fukari. Amsterdam and Philadelphia: John Benjamins, 93-107.

JACQUEMOND, Richard. 1992. "Translation and Cultural Hegemony: The case of French-Arabic Translation». En Rethinking Translation: Discourse Subjectivity Ideology, ed. por Lawrence Venuti. London: Routledge, 139-159.

KOSTER, Cees. 2010. "Comparative approaches». En Handbook of Translation Studies. Vol. 2, ed. por Yves Gambier y Luc van Doorslaer. Amsterdam/Philadelphia: John Benjamins Publishing Company, 21-25.

KRUGEN, Haidee. 2012. Postcolonial polysistems. The production and reception of translated children's literature in South Africa. Amsterdam/Philadelphia: John Benjamins

LEFEVERE, André. 1997. Traducción, reescritura y la manipulación del canon literario. [orig. Translation, rewriting, and the manipulation of literary frame]. Traducido por África Vidal y Román Álvarez. Salamanca: Ediciones Colegio de España.

LÓPEZ GARCíA, Dámaso. 2007. «Hergé, Tintín y las traducciones». Peonza: revista de literatura infantil y juvenil, 83 /Ejemplar dedicado a la traducción, 33-39.

MAALOUF, Amin. 1988. León el Africano. [orig. Léon l'Africain]. Traducido por M. a Teresa Gallego Urrutia M. ${ }^{a}$ Isabel Reverte Cejudo. Madrid: Alianza.

MAílLO, Felipe. 2004. La desaparición de Al-Ándalus. Madrid: Abada.

MEHREZ, Samia. 1992. "Translation and the post-colonial experience: the francophone North African text». En Rethinking Translation: Discourse Subjectivity Ideology, ed. por Lawrence Venuti. London: Routledge, 120-138.

MERNISSI, Fatima. 1994. Sueños en el umbral. Memorias de una niña del harén. [orig. Dreams of trespass. Tales of a harem girlhood]. Traducido por Ángela Pérez. Madrid: Muchnik.

PICKFORD, Susan. 2016. «The Factors Governing the Availability of Maghrebi Literature in English: A Case Study in the Sociology of Translation», CLINA 2 (1): 77-94.

RIDAO, José María. 2005. «León el Africano, hombre de frontera», El País, 18 de septiembre de 2005. Acceso el 13 de julio de 2017. https://elpais.com/diario/2005/09/18/ cultura/1126994408_850215.html

Beatriz SOTO ARANDA Traducir literatura infantil y juvenil de temática árabe e islámica al castellano: editoriales, normas preliminares y polisistemas literarios en contacto 
RodrígueZ MAgdA, Rosa M. ${ }^{a}$. 2008. Inexistente Al Ándalus: De Cómo Los Intelectuales Reinventan El Islam. Oviedo: Nobel.

SELIM, Samah. 2009. "Nation and Translation in the Middle East Histories, Canons, Hegemonies», The Translator, 15 (1): 1-13. Fecha de acceso 15 de noviembre de 2018 https://www. eume-berlin.de/fileadmin/eume/pdf/arbeitsgespraeche/selim_nation_translation.pdf

SOTO ARANDA, Beatriz. 2017a. La traducción de literatura infantil y juvenil de temática árabe e islámica al castellano: ideología y recepción. Tesis doctoral. Universidad Jaume I de Castellón.

SOTO ARANDA, Beatriz. 2017b. «La no traducción: el silenciamiento de la agencia o el efecto perverso de la traducción de la literatura infantil y juvenil (LIJ)». Revista Iberoamericana de Lingüística RIL 12: 5-33.

SOTO ARANDA, Beatriz. 2018. "De la representación a la construcción de la Otredad: traducir del árabe a los colguages occidentales». Tonos digital: revista electrónica de estudios filológicos 35, Fecha de acceso 10 de noviembre de 2018 https://digitum.um.es/xmlui/ bitstream/10201/60528/1/2011-5723-1-PB.pdf

STEARNS, Justin. 2009. «Representing and Remembering al-Andalus: Some Historical Considerations Regarding the End of Time and the Making of Nostalgia». Medieval Encounters, 15 (2-4): 355-374.

StURGE, Kate. 2007. Representing Others. Translation, Ethnography and the Museum. Manchester: St. Jerome.

VALERO CUADRA, Pino. 2010. «Las traducciones al español de literatura intercultural alemana». Revista de filología alemana, Extra 3 (III): 301-309. Fecha de acceso 10 de noviembre de 2018. http://revistas.ucm.es/index.php/RFAL/article/viewFile/36606/35439

VEGA, M. ${ }^{a}$ José. 2003. Imperios de papel. Introducción a la crítica postcolonial. Crítica: Barcelona.

VENUTI, Lawrence.1998. The Scandals of Translation. Towards an ethics of difference. London: Routledge.

WOLF, Michaela. 2000. «The Third Space in Postcolonial Representation». En Changing the Terms. Translating in the Postcolonial Era, ed. por Sherry Simon y Paul St.-Pierre, Ottawa: University of Ottawa Press, 127-146.

WOLF, Michaela. 2007a. «Introduction». En Constructing a Sociology of Translation, ed. por Michaela Wolf y Alexandra Fukari. Amsterdam: John Benjamins. 1-38.

WOLF, Michaela. 2007b. «The location of the translation field. Negotiating borderlines between Pierre Bourdieu and Homi Bhabha". En Constructing a Sociology of Translation, ed. por Michaela Wolf y Alexandra Fukari. Amsterdam: John Benjamins, 109-122.

Beatriz SOTO ARANDA

Traducir literatura infantil y juvenil de temática árabe e islámica al castellano: editoriales, normas preliminares y polisistemas literarios en contacto
CLINA

vol. 5-1, June 2019, 113-130

elSSN: 2444-1961

Ediciones Universidad de Salamanca - CC BY-NC-ND 